\title{
$A \mathrm{~T}^{+6}$ to $\mathrm{C}^{+6}$ mutation in the donor splice site of COL3A1 IVS7 causes exon skipping and results in Ehlers-Danlos syndrome type IV
}

\author{
Jan Lloyd, Paolo Narcisi, Allan Richards, F Michael Pope
}

\begin{abstract}
Ehlers-Danlos syndrome type IV is usually caused by mutations in COL3A1, the gene coding for type III collagen. In a woman with a milder form of this disease, analysis of type III collagen synthesised by her cultured skin fibroblasts showed an apparently shorter form of the protein. Amplification of overlapping cDNAs, encoding the triple helical region of the molecule, showed a deletion near the 5 ' end of the gene. Sequencing showed that exon 7 was missing from the cDNA sequence.

Analysis of genomic DNA showed that this was the result of a $T^{+6}$ to $C^{+6}$ mutation in the donor splice site of intron 7. The proband's parents and 35 normal controls were homozygous for $T^{+6}$ at this position, indicating that the $\mathrm{C}^{+6}$ mutation was causative.

( $\mathcal{A}$ Med Genet 1993;30:376-80)
\end{abstract}

Of the various types of Ehlers-Danlos syndrome the most severe is type IV (EDS IV). ${ }^{1}$ Patients with this disease can present with a variety of clinical signs. These range from the severe acrogeric type with generalised thin skin, a pinched nose, thin lips, lobeless ears, and premature ageing, to a relatively mild phenotype with variably thin skin, joint laxity, and subtle facial features reminiscent of the more severe phenotype. Fragile blood vessels and hollow organs make EDS IV particularly life threatening, in both the severe and mild forms alike.

Early studies showed that fibroblasts from EDS IV patients secreted lower than normal amounts of type III procollagen. ${ }^{2}$ Later, the disease was linked to $\operatorname{COL} 3 \mathrm{~A} 1$, the gene encoding this protein. ${ }^{3}$ More recently, with the publication of full length cDNA sequence and partial characterisation of the gene structure, detailed analysis of mutations in EDS IV patients has become possible. Defects have included point mutations, ${ }^{4-7}$ large and small deletions, ${ }^{8-10}$ and faulty processing of premRNA. ${ }^{11-14}$ Most exon skipping mutations have had $\mathrm{G}^{+1}$ to $A$ substitutions in donor splice sites, causing severe EDS IV. Exceptions are an IVS25 $\mathrm{G}^{+5}$ to $T$ substitution which caused severe EDS IV, ${ }^{14}$ and an IVS20 $\mathrm{G}^{+1}$ to A mutation, which resulted in phenotypical overlap between EDS IV and familial aortic aneurysms. ${ }^{11}$

Here we have characterised a new exon skipping mutation of COL3A1. Despite only mild external signs of EDS IV the patient had several dissecting aneurysms. A substitution of IVS7 $\mathrm{T}^{+6}$ led to skipping of exon 7 . This is the most $5^{\prime}$, completely triple helix encoding exon, of type III collagen, since exon 6 codes partially for the $\mathrm{N}$-peptidase cleavage site and the first nine amino acids of the triple helix.

\section{Materials and methods}

THE PATIENT

A 32 year old woman presented with severe right sided abdominal pain suggestive of renal colic. Ultrasound examination showed an infarcted right kidney. Later she developed intermittent claudication of the left leg which improved and eventually disappeared. Angiography showed a right sided renal artery occlusion with an aberrantly supplied lower pole. The left iliac artery was stenosed with a possible dissection. Earlier, while still a student, she developed a transient hemiparesis which was attributed to migraine but with a slightly abnormal arch angiogram. Four years before her renal problems she perforated her bowel shortly after the delivery of her only child by caesarean section. She had varicose veins since teenage which, although surgically treated three times, had relapsed. Her parents, a sister, and son were clinically normal.

On clinical examination she had large eyes, lobeless ears, slightly thin skin over the dorsum of the hands with flattened finger pulps. There was capillary prominence over the shoulders and sacrum, loose jointedness of the knees and wrists, and minor varicose veins. She was classified as having mild vascular nonacrogeric EDS IV.

\section{PROTEIN ANALYSIS}

Fibroblast cell cultures were established, grown, labelled, and the procollagens and collagens analysed as previously described..$^{15}$

CDNA SYNTHESIS AND AMPLIFICATION

Total cytoplasmic RNA was isolated from cultured skin fibroblasts by lysing with Nonidet $\mathrm{P}-40$ in the presence of vanadyl ribonucleoside complex. ${ }^{16}$ First strand cDNA synthesis was performed as described previously ${ }^{6}$ using one of five antisense primers (see below). Synthesised cDNAs were then amplified as previously described, ${ }^{6}$ by the polymerase chain reaction, ${ }^{17}$ using the appropriate pair of primers. Those products for which sequencing was required were blunt end ligated into 
CB peptides
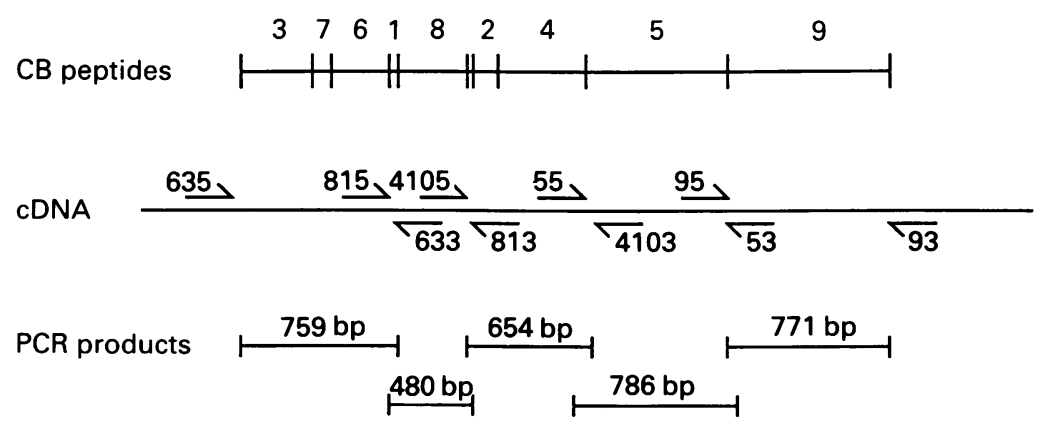

Figure 1 Schematic representation of type III collagen $c D N A$ and the position of oligonucleotides. The helical region of type III collagen is represented by the upper line. The position of the cyanogen bromide peptides is indicated, except CB10, which is situated between $C B 8$ and CB2. The site of each oligonucleotide is indicated by the arrows which also show their direction $5^{\prime}$ to $3^{\prime}$. The size of five overlapping $c D N A$ $P C R$ products are shown as bars below the cDNA.

M13mp18 after treatment with polynucleotide kinase to phosphorylate their $5^{\prime}$ termini.

OLIGONUCLEOTIDE PRIMERS USED FOR CDNA AMPLIFICATION

The primers CB4103 and CB4105 were used to amplify cDNA encoding peptides CB4, CB2, and CB10. Similarly, the primers CB813 and CB815 were used to amplify cDNA for peptides CB8 and CB1, while primers CB633 and CB635 amplified CB6, CB7, and CB3. The first nine base pairs of each oligonucleotide code for an EcoRI restriction enzyme site.

CB4103 5'GGGGAATTCAGGACTTCCAAGACCTCCTCTTTC3' -antisense

CB4105 5'GGGGAATTCAGAGATGGCGTCCCTGGAGGTCCA3' - sense

CB813 5'GGGGAATTCTGGACTTCCGGGCATGCCCCTCAT3' -antisense

CB815 5'GGGGAATTCAATGGTAGTCCTGGTGGTAAAGGC3' - sense
A

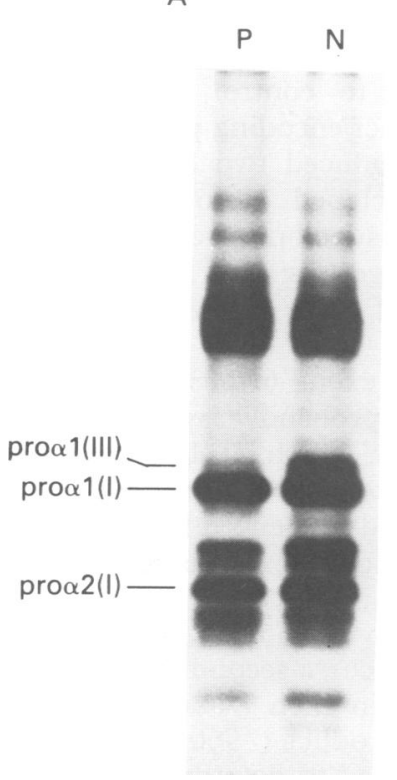

B

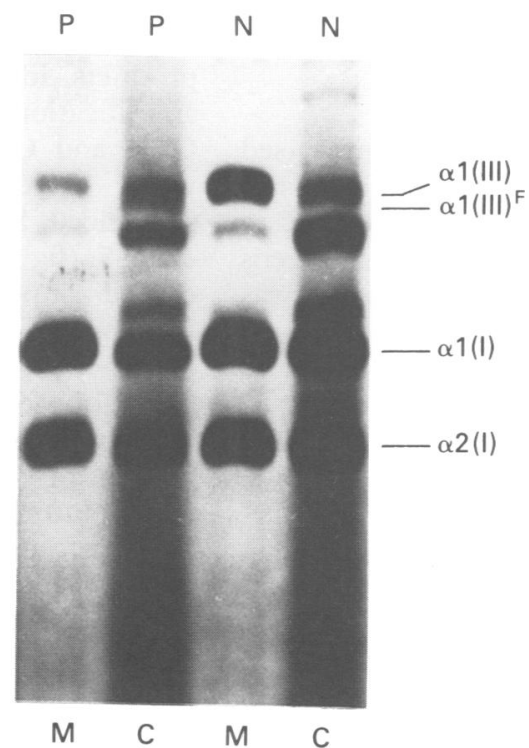

Figure 2 Analysis of procollagens and collagens. (A) Procollagens obtained from the medium of cultured fibroblasts of the proband $(P)$ or a normal control $(N)$ were analysed by SDS-PAGE and fluorography. (B) Pepsin treated collagens obtained from either the medium $(M)$ or cell layer $(C)$ of cultured fibroblasts of the proband $(P)$ or normal control $(N)$ were analysed by SDS-PAGE. The extra band present in the proband's cell layer is labelled $\alpha 1$ (III $)^{F}$.
CB633 5'GGGGAATTCTCCAGGAATGCCAGCGGGACCCAT3' -antisense

CB635 5'GGGGAATTCGATGTCAAGTCTGGAGTAGCAGTA3' - sense

Primers used to amplify cDNA encoding CB9 and $\mathrm{CB} 5$ were as previously described. ${ }^{610}$ Their positions are shown in fig 1 .

GENOMIC DNA AMPLIFICATION

Two different genomic DNA products, containing either the whole 54 bp exon 7 or part of it, were amplified for sequencing. The larger $(\sim 1560 \mathrm{bp})$ product was synthesised using primers within exon 6 (CB635, see above) and exon 8 (E8, see below). This was incubated with the restriction enzyme $R s a I$ and the fragments blunt end ligated into M13mp18 before sequencing.

A smaller genomic DNA fragment ( $560 \mathrm{bp}$ ) was amplified using the primers E7 5'GGTACATCTGGTCATCCTGGTTCC3' - sense and E8 5'AGGGGGTCCTTGGTATCCTGGAGA3'-antisense. These amplified the $3^{\prime}$ end of exon 7 , intron 7 , and the $5^{\prime}$ end of exon 8. This was also blunt end ligated into $\mathrm{M} 13 \mathrm{mp} 18$.

Amplification of these DNA fragments was achieved through 10 cycles consisting of $95^{\circ} \mathrm{C}$ for 1.5 minutes, $60^{\circ} \mathrm{C}$ for 1.5 minutes, and $72^{\circ} \mathrm{C}$ for four minutes followed by an additional 30 cycles consisting of $95^{\circ} \mathrm{C}$ for one minute, $60^{\circ} \mathrm{C}$ for one minute, and $72^{\circ} \mathrm{C}$ for three minutes.

SEQUENCING

Individual subclones were sequenced using Sequenase (United States Biochemicals Corp) as described by the manufacturer.

ALLELE SPECIFIC OLIGONUCLEOTIDE (ASO) HYBRIDISATIONS

Amplified genomic DNA from the proband, various members of her family, and normal controls were slot blotted in duplicate onto nitrocellulose and hybridised to ASOs coding for either IVS7 $T^{+6} \quad 5^{\prime}$ GGTTCCCCTGT-

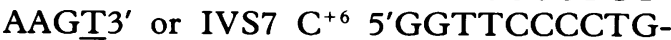

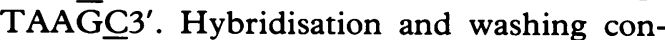
ditions were essentially as described by Wood et al. ${ }^{18}$

Briefly, prehybridisation was at $37^{\circ} \mathrm{C}$ for 16

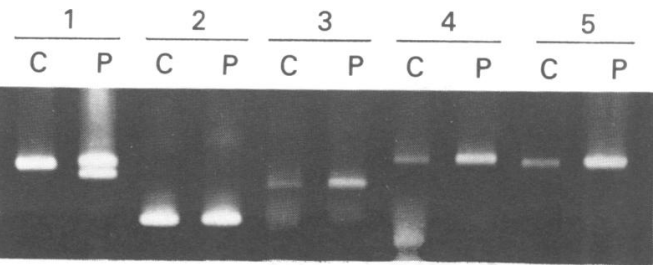

Figure 3 Amplification of $c D N A$ for the entire helical region of type III collagen. $c D N A$ encoding peptides $C B 3, C B 7$, and $C B 6$ (1), $C B 1$ and $C B 8$ (2), $C B 10$, $C B 2$, and $C B 4$ (3), $C B 5$ (4), and $C B 9$ (5) were amplified using RNA from the patient (P) and $a$ normal control ( $C)$. The products were then subjected to electrophoresis in an agarose gel. 


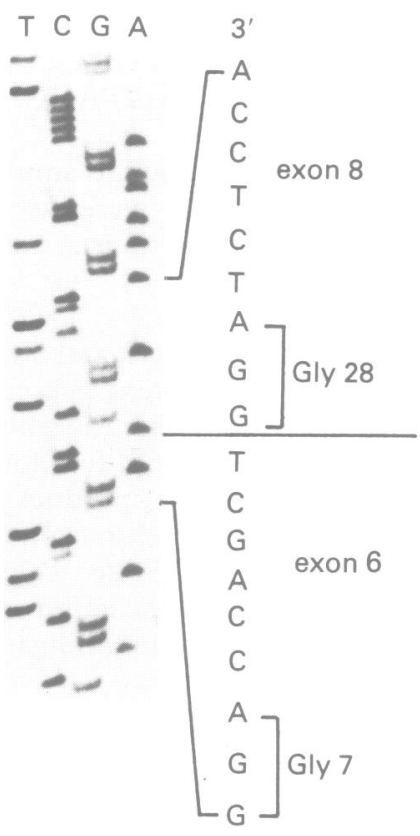

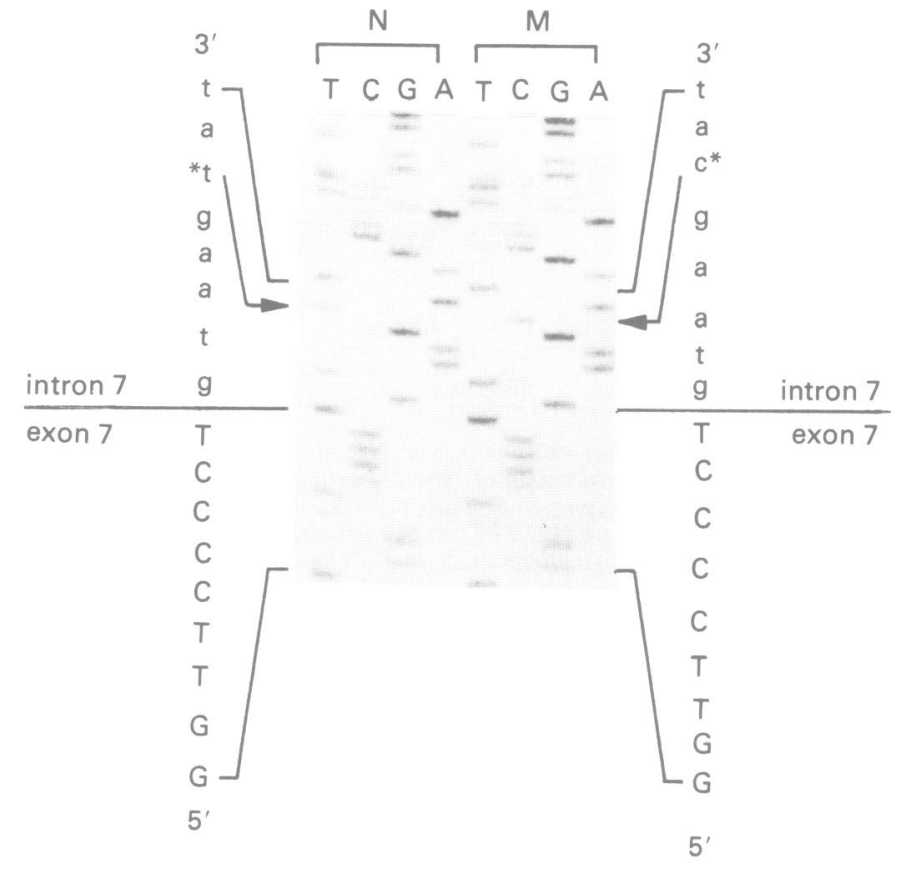

Figure 4 Sequences of $c D N A$ and genomic DNA obtained from the patient. Analysis of amplified cDNA (left) showed clones lacking exon 7. Sequencing of amplified genomic DNA (right) showed that the +6 position of the donor splice site was either a $T$ or $C$. Intron sequences are in lower case.

hours in $0.9 \mathrm{~mol} / 1 \mathrm{NaCl} / 0.09 \mathrm{~mol} / 1 \mathrm{Na}$ citrate (6 $\times \mathrm{SSC}), \quad 50 \mathrm{mmol} / 1$ sodium phosphate pH $6 \cdot 8,5 \times$ Denhardt's solution $(1 \mathrm{mg} / \mathrm{ml}$ each of albumin, polyvinylpyrrolidone, Ficoll), and yeast tRNA at $0.1 \mathrm{mg} / \mathrm{ml}$. Hybridisation was in the same solution containing a labelled ASO. After hybridisation the filters were rinsed three times in $6 \times \mathrm{SSC}$ at $4^{\circ} \mathrm{C}$ and then washed twice for 30 minutes in $6 \times \mathrm{SSC}$ at $4^{\circ} \mathrm{C}$. The filters were then rinsed twice with $3 \mathrm{~mol} / \mathrm{l}$ $\mathrm{Me}_{4} \mathrm{NCl}, \quad 50 \mathrm{mmol} / 1$ Tris- $\mathrm{HCl}$ pH 8.0, $2 \mathrm{mmol} / 1 \mathrm{EDTA}, 0 \cdot 1 \% \mathrm{SDS}$ at $37^{\circ} \mathrm{C}$, followed by two washes in the same solution at $47-48^{\circ} \mathrm{C}$ for 20 minutes. At each stage the filters were washed separately.

\section{Results and discussion}

Initial analysis of the procollagens synthesised by the patient's cultured skin fibroblasts showed poor secretion of type III procollagen (fig 2A). When the pepsin treated collagens were examined, an extra protein band was visible in the patient's samples. It was retained intracellularly and migrated slightly faster in

\section{1rattcatttattttgtttttcattcaaattcacattcc exon 7 agGGCCCCCCAGGCCCTCCCGGTCCCCCTGGTACATCTG}

\section{GTCATCCTGGTTCCCCTgtaag $\mathbf{t}^{\mathrm{C}}$ atagc -1 t tacttta exon 8 \\ aattatttacatattctactcacagGGATCTCCAGGAT}

\section{ACCAAGGACCCCCT}

Figure 5 Splice site sequences adjacent to exon 7. Exon sequences are shown in bold capitals, intron sequences are in lower case. Donor and acceptor splice sites and possible lariat branch points are shown in bold type. IVS $7^{+6}$ is either T or C.
SDS-polyacrylamide gel electrophoresis than normal $\alpha 1$ (III) chains, giving the appearance of a broad band (fig $2 \mathrm{~B}$ ). These results suggested synthesis of a shortened form of type III collagen which was very poorly secreted. To test this hypothesis cDNA encoding the entire triple helical region of type III collagen was amplified to detect possible deletions.

The cDNA was amplified as five overlapping products (fig 1). These had originally been designed to encode complete cyanogen bromide peptides, for use in combination with peptide mapping of mutations. ${ }^{6710}$ This time localisation of the mutation was possible without previous peptide mapping (fig 3). Whereas four of the primer pairs produced amplified products identical to control samples, the amplification product encoding peptides $\mathrm{CB} 6$, CB7, and CB3 produced two bands. These were therefore cloned into $\mathrm{M} 13$ and sequenced. Several subclones lacked the $54 \mathrm{bp}$ exon 7 (fig 4) suggesting that the mutation caused skipping of this exon during RNA splicing.

Genomic DNA (exons 6 to 8 of COL $3 A 1$ $\sim 1560 \mathrm{bp}$ ) from the proband was amplified and cut with RsaI, for which at least one site occurred (within exon 7). The products were cloned into M13 and sequenced to analyse the donor/acceptor splice sites flanking exon 7 . Because of a bias in the type of subclones obtained (only two produced the intron 7 donor splice sequence), a second amplification using primers within exon 7 and exon 8 was performed. This product $(\sim 560 \mathrm{bp})$ was also cloned and sequenced to determine the IVS7 donor splice sequence which was under-represented in subclones of the larger PCR product.

Sequencing showed that the donor/acceptor splice sites of the patient's two alleles differed only at $\mathrm{IVS}^{+6}$ which was either a T or C 
Mutant $\mathrm{C}^{+6}$

A

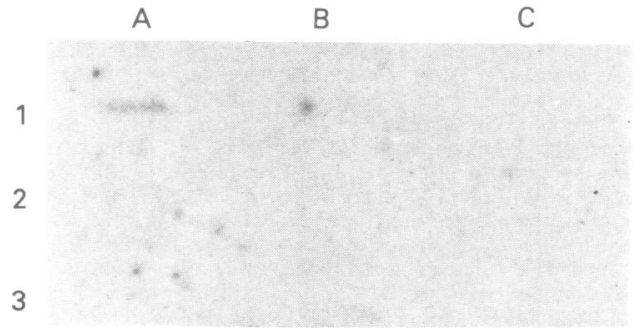

Normal $\mathrm{T}^{+6}$

A

B

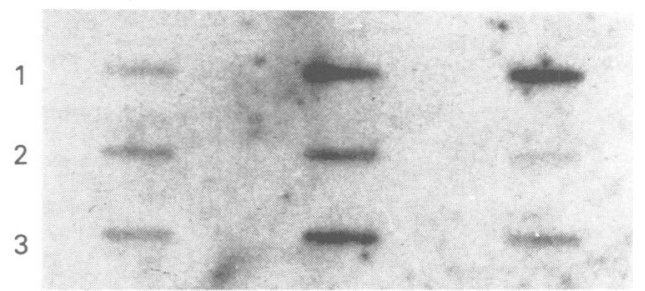

Figure 6 ASO hybridisations. Amplified DNA from the patient (A1), her mother (B1), father (C1), son (A2), and sister (B2), and normal controls (C2, A3, B3, C3) were slot blotted onto nitrocellulose and hybridised to either IVST $C^{+6}$ or IVS7 $T^{+6}$ as indicated.

residue (figs 4 and 5). Because this position is redundant in the consensus vertebrate $5^{\prime}$ donor splice sequence, ${ }^{19} 20$ immediate members of the proband's family and 35 controls were tested with ASOs. The region was amplified, slot blotted, and hybridised to ASOs coding for either IVS7 $\mathrm{T}^{+6}$ or IVS7 $\mathrm{C}^{+6}$. After washing with tetramethylammonium chloride the filters were autoradiographed (fig 6). Whereas IVS7 $\mathrm{T}^{+6}$ hybridised to all samples, IVS7 $\mathrm{C}^{+6}$ annealed only to DNA from the proband. Thirty-five unrelated control samples (data are only shown for four), and more notably her unaffected parents, did not possess the $\mathrm{C}^{+6}$ sequence, neither did her clinically normal son and sister.

This IVS7 $\mathrm{T}^{+6}$ to $\mathrm{C}^{+6}$ transversion of COL $3 A 1$, like the more common $\mathrm{G}^{+1}$ mutations previously described in this gene, ${ }^{11-13}$ alters the donor splice site consensus sequence $\mathrm{A}^{-2} \mathrm{G}^{-1} / \mathrm{G}^{+1} \mathrm{~T}^{+2} \mathrm{~A}^{+3} \mathrm{~A}^{+4} \mathrm{G}^{+5} \mathrm{~T}^{+6},{ }^{20}$ and causes the preceding exon to be skipped. The +6 position can be redundant in the donor splice site; however, when the -1 and -2 positions are not $A G$ then the $+4,+5$, and +6 positions tend to conform to the consensus. ${ }^{21}$ In the case of exon 7 of COL3A1 the last two nucleotides are CT and so presumably a $T^{+6}$ becomes essential for recognition by U1RNA, which binds to the donor site during normal splicing. ${ }^{22}$ Similar observations have been made for IVS $1 \mathrm{~T}^{+6}$ of the $\beta$ globin gene, ${ }^{23} \mathrm{IVS} 25 \mathrm{G}^{+5}$ of COL $3 A 1,{ }^{14}$ IVS14 $\mathrm{G}^{+5}$ of COL1A1, ${ }^{24}$ and IVS33 $\mathrm{G}^{+5}$ of COL1A2. ${ }^{25}$ These cause $\beta^{+}$ thalassaemia, EDS IV, and osteogenesis imperfecta (COL1A1 and COL1A2) respectively.

Mutations of $\mathrm{G}^{+1}$ to $A$ in various introns of COL3A1 can produce quite different splicing patterns. Either high levels of exon skipping or insertion of in frame intron sequences are produced by different mutations. ${ }^{12}$ Experiments to determine the splicing pattern from the IVS7 $\mathrm{C}^{+6}$ and other exon skipping mutations in COL $3 \mathrm{~A} 1$ are in progress. Most of the shortened form of type III collagen, produced by the proband's fibroblasts, appears to be retained within the cell layer. This is in contrast to a nine amino acid deletion which is efficiently secreted and causes a more severe clinical phenotype. ${ }^{10}$ In vivo the $\mathrm{N}$-terminal position of this deletion may also contribute to the mild phenotype as most of the helix Cterminal to this exon will fold normally, from the $\mathrm{C}$ - to the $\mathrm{N}$-terminal end. This is in contrast to C-terminal deletions which cause overmodification of the helix $\mathrm{N}$-terminal to the site of mutation. ${ }^{13}$

In summary, unlike most exon skipping mutations of COL $3 \mathrm{~A} 1$, this patient does not have the acrogeric form of EDS IV, but more closely resembles the IVS $20 \mathrm{G}^{+1}$ to A mutation which presented with phenotypic overlap between EDS IV and aortic aneurysms. Why these two mutations produce a milder phenotype is unclear but it is likely to be complex and involve patterns of missplicing, secretion of abnormal protein from the cell, and position within the collagen helix.

We would like to thank Mrs Olive Cutting for technical assistance in tissue culture, and the Medical Illustration Department at the CRC for production of the figures.

1 Beighton P. The Ehlers-Danlos syndrome. London: Heinemann Medical Books, 1970.

2 Pope FM, Martin GR, Lichtenstein JR, et al. Patients with Ehlers-Danlos syndrome type IV lack type III collagen. Proc Natl Acad Sci USA 1975;72:1314-16.

3 Tsipouras P, Byers PH, Schwartz RC, et al. Ehlers-Danlos syndrome type IV: cosegregation of the phenotype to a COL3A1 allele of type III procollagen. Hum Genet 1986;74:41-6.

4 Tromp G, Kuivaniemi H, Shikata H, Prockop DJ. A single base mutation that substitutes serine for glycine 790 of the $\alpha 1$ (III) chain of type III collagen exposes an arginine and causes Ehlers-Danlos syndrome type IV. $f$ Biol Chem 1989;264:1349-52.

5 Tromp G, Kuivaniemi H, Stolle C, Pope FM, Prockop DJ. Single base mutation in the type III procollagen gene that converts the codon for glycine 883 to aspartate in a mild variant of Ehlers-Danlos syndrome IV. $f \mathrm{Biol}$ Chem 1989;264:19313-17.

6 Richards AJ, Lloyd JC, Ward PN, De Paepe A, Narcisi P, Pope FM. Characterisation of a glycine to valine substitution at amino acid 910 of the triple helical region of type III collagen in a patient with Ehlers-Danlos syndrome type IV. $\mathcal{F}$ Med Genet 1991;28:458-63.

7 Richards AJ, Ward PN, Narcisi P, Nicholls AC, Lloyd JC, Pope FM. A single base mutation in the gene for type III collagen (COL3A1) converts glycine 847 to glutamic acid collagen (COL 3A1) converts glycine 847 to glutamic acid
in a family with Ehlers-Danlos syndrome type IV. An in a family with Ehlers-Danlos syndrome type IV. An unaffected family member is

8 Lee B, D'Alessio M, Vissing H, Ramirez F, Steinmann B, Superti-Furga $A$. Characterization of a large deletion associated with a polymorphic block of repeated dinucleotides in the type III procollagen gene (COL 3A1) of a patient with Ehlers-Danlos syndrome type IV. Am f Hum Genet 1991;48:511-17.

9 Vissing H, D'Alessio M, Lee B, et al. Multiexon deletion in the procollagen III gene is associated with mild EhlersDanlos syndrome type IV. 7 Biol Chem 1991;266:5244-8.

10 Richards AJ, Lloyd JC, Narcisi P, et al. A 27 bp deletion from one allele of the type III colle al. A 27 bene delion a large family with Ehlers-Danlos syndrome type IV. Hum Genet 1992;88:325-30.

11 Kontusaari S, Tromp G, Kuivaniemi H, Ladda RL, Prockop DJ. Inheritance of an RNA splicing mutation $G$ in the type III procollagen gene (COL3A1) in a family having aortic aneurysms and easy bruisability: phenotypic overlap between familial arterial aneurysms and Ehlers-Danlos syndrome type IV. Am f Hum Genet 990;47:112-20.

12 Kuivaniemi H, Kontusaari S, Tromp G, Zhao M, Sabol C, Prockop DJ. Identical $G^{+1}$ to $A$ mutations in three different introns of the type III procollagen gene (COL 3A1) produce different patterns of RNA splicing in 
three variants of Ehlers-Danlos syndrome IV. I Biol three variants of Ehlers-

13 Cole WG, Chiodo AA, Lamande SR, et al. A base substitution at a splice site in the COL $3 \mathrm{~A} 1$ gene causes exon
skipping and generates abnormal type III procollagen in a patient with Ehlers-Danlos syndrome type IV. $\boldsymbol{f}$ Bio patient with Ehlers-Danlos

14 Lee B, Vitale E, Superti-Furga A, Steinmann B, Ramirez F. $G$ to $T$ transversion at position +5 of a splice donor site causes skipping of the preceding exon in the type II procollagen transcripts of a patient with Ehlers-Danlos syndrome type IV. $\mathcal{f}$ Biol Chem 1991;266:5256-9.

15 Nicholls AC, De Paepe A, Narcisi P, et al. Linkage of a polymorphic marker for the type III collagen gen (COL 3A1) to atypical autosomal dominant Ehlers-Danlos syndrome type IV in a large Belgian pedigree. Hum Genet 1988;78:276-81.

16 Maniatis T, Fritsch EF, Sambrook J. Molecular cloning: a laboratory manual. Cold Spring Harbor, NY: Cold Spring

17 Saiki RK, Scharf S, Faloona F, et al. Enzymatic amplification of $\beta$-globin genomic sequences and restriction site analysis for diagnosis of sickle cell anemia. Science 1985;230:1350-

18 Wood WI, Gitschier J, Lasky LA, Lawn RM. Base composition independent hybridization in tetramethyl ammonium chloride: a method for oligonucleotide screening of highly complex gene libraries. Proc Natl Acad Sci USA 1985;82:1585-8.

19 Breathnach R, Chambon P. Organisation and expression of eucaryotic split genes coding for proteins. Annu Rev Biochem 1981;50:349-83.

20 Krainer AR, Maniatis T. RNA splicing. In: Hames BD, Glover DM, eds. Transcription and splicing. Oxford: IRL Press, 1988:131-206.

21 Jacob M, Gallinaro $H$. The $5^{\prime}$ splice site: phylogenetic evolution and variable geometry of association with U1RNA. Nucleic Acids Res 1989;17:2159-80.

22 Mount SM, Pettersson I, Hinterberger M, Karmas A, Steitz JA. The U1 small nuclear RNA-protein complex
selectively binds a 5' splice site in vitro. Cell 1983;33:50918.

23 Treisman R, Orkin SH, Maniatis T. Specific transcription and RNA splicing defects in five cloned $\beta$-thalassaemia genes. Nature 1983;302:591-6.

24 Bonadio J, Ramirez F, Barr M. An intron mutation in the human $\alpha 1(\mathrm{I})$ collagen gene alters the efficiency of prehuman $\alpha 1(I)$ collagen gene alters the efficiency of premRNA splicing and is associated with osteogen
imperfecta type II. F Biol Chem 1990;265:2262-8.

25 Ganguly A, Baldwin CT, Strobel D, Conway D, Horton W, Prockop DJ. Heterozygous mutation in the $\mathrm{G}^{+5}$ position of intron 33 of the pro- $\alpha 2$ (I) gene (COL1A2) that causes aberrant RNA splicing and lethal osteogenesis imperfecta. F Biol Chem 1991;266:12035-40. 